\title{
Airborne Electromagnetic and Magnetic Surveying in the Search for Kimberlites
}

\author{
Kilty, S. J. \\ Geoterrex-Dighem Pty Limited, Sydney Australia
}

\section{Extended Abstract}

In aerial geophysical surveying four physical parameters of the underlying ground can be measured, namely magnetic susceptibility, radioactivity, conductivity and density. Airborne detectors capable of measuring magnetic susceptibility have been used since the 1940 's, conductivity and radioactivity since the 1950's and gravity since the 1980's. The measurement of both magnetics and electromagnetics are mature sciences that when properly utilized can detect conductive and or magnetic targets that are relatively small both in aerial extent and in physical property contrast relative to the host rocks. Radiometrics is a mature science but lacks sufficient resolution to detect small targets such as pipes. Airborne gravity is presently an immature method and as yet does not have the resolution to detect features much smaller than 2 kilometers in spatial extent or the small density contrast ( $>2 \mathrm{mgal}$ ) between most host rocks and kimberlite.

Aeromagnetic surveying has been used extensively for the detection of kimberlite pipes and is recognized as being an essential part of any exploration program. This method requires a susceptibility contrast between the kimberlite rock and the host rock. Aeromagnetics is most useful where kimberlites have been intruded into rocks that have a low magnetic susceptibility such as sandstone or other sedimentary rocks. An exception to this is where laterites have been formed and magnetite concentration at the surface resulting from this weathering process may hide weak responses from kimberlites. Magnetic responses are more difficult to interpret when the area of interest to the explorationist contains volcanic rocks. In addition a kimberlite may have a magnetic signature which is negative, positive or neutral with respect to the host rock such it's detection is often impossible.

Airborne electromagnetics has been used for the detection of kimberlites since the mid 1970's both in Africa and in Canada. Macnae described the use of Input for kimberlite exploration in a program in South Africa in 1976. Selco used Input extensively for kimberlite exploration in the James Bay Lowlands of Northern Ontario through out the 1970's.

The widespread use of combined electromagnetic and magnetic surveys commenced in 1991 when BHP and Diamet employed the five frequency helicopter borne Dighem system (Figure 1) as the primary exploration tool in the Lac de Gras area of Northern Canada. 


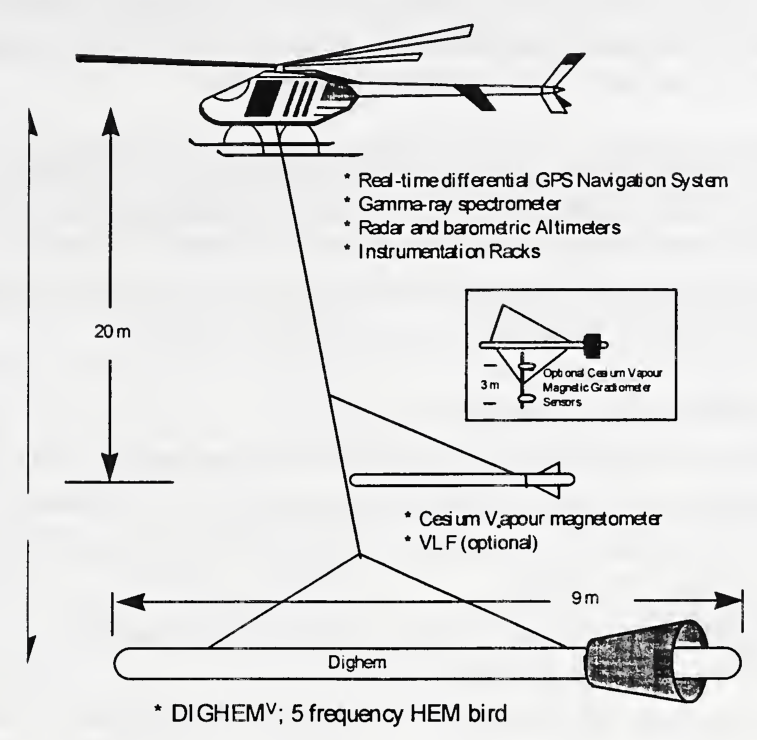

Figure 1

Chuck Fipke first noted the potential of the area for containing kimberlites when he used geochemical methods to trace the glacial dispersion train of diamond indicator minerals from the Mackenzie Valley to Lac de Gras. Diamond and ilmenite indicators in a glaciated terrain are resistive to mechanical destruction and allowed Fipke to target an area at a distance greater than 800 kilometers from where he began his search. However, the area identified by Fipke was over 10,000 square kilometers in size. At this stage, a small helicopter borne Dighem electromagnetic survey was commissioned to try to directly detect any pipes in the area. The Point Lake discovery pipe was mapped by the electromagnetic system on the first survey flight.

Airborne electromagnetic surveying has become a standard exploration tool for diamond exploration. To date over 200,000 line kilometers of fixed wing $\left(\mathrm{GEOTEM}^{\mathrm{tm}}\right)$ and helicopter borne (Dighem) surveys have been flown in the Lac de Gras area. Several conductive but non-magnetic kimberlites have been identified on these combined surveys. Exploration in the area is unique in that due to glaciation, the area has been pockmarked wherever the glaciers passed over softer rocks. These pockmarks subsequently filled with melt water to form extensive lake systems. Up to $25 \%$ of the exploration areas is covered by these lakes. As kimberlite is a soft rock, the majority of kimberlites are also hidden beneath lakes. 
The Dighem system was re-introduced to Australia in 1994 primarily to carry out Kimberlite exploration programs. Dighem surveys have been carried out over Argyle (RTZ), the Merlin project (Ashton), Beta Creek and Seppelt (Striker Resources) and over several areas in the Yilgarn. In addition to direct detection of pipes, resistivity and depthto-conductor maps have been generated from the electromagnetic data in order to map palaeochannels that could contain alluvial diamond deposits.

Airborne electromagnetic surveying for diamond exploration differs from other applications in the line spacing, the selection of frequencies and unique interpretation techniques that can differentiate between kimberlites and other conductive bodies.

Several criteria are used for evaluating the electromagnetic and magnetic signature to determine if it could be due to a kimberlitic body. These include;

- Both a electromagnetic and a magnetic response

- A bulls-eye appearance to the magnetic and/or electromagnetic contours

- A characteristic double peak on co-axial and single peak on co-planar EM data

- When both EM and magnetic responses are present the EM response will be from a shallower source than the magnetics

- More than one anomaly will be present due to clustering of pipes

- Association with a circular topographic feature

- Generally a high amplitude response at the higher EM frequencies

Examples of these characteristics are evident in data sets from pipes in the Lac de Gras area of Canada and the Beta Creek and Merlin areas in Australia.

A second use of electromagnetics is the mapping of palaeochannels. Examples of palaeochannel mapping from the Yilgarn area of Western Australia clearly indicate the presence of old streambeds.

\section{References}

Buckle, J. 1993 Detection of Kimberlite Pipes in the Lac de Gras Area, Unpublished

Macnae, James C., Kimberlites and Exploration Geophysics, Geophysics, Vol 44, August 1979, P.13951416.

O’Neill, Adam John, 1994, Geophysical Exploration for Diamonds, Thesis, Curtin University of Technology 